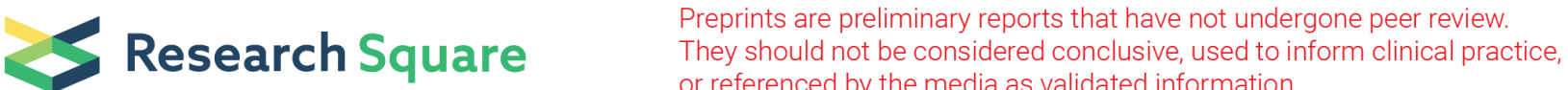

\section{Short-Term Impact of Ambient Temperature on the Incidence of Influenza in Wuhan, China}

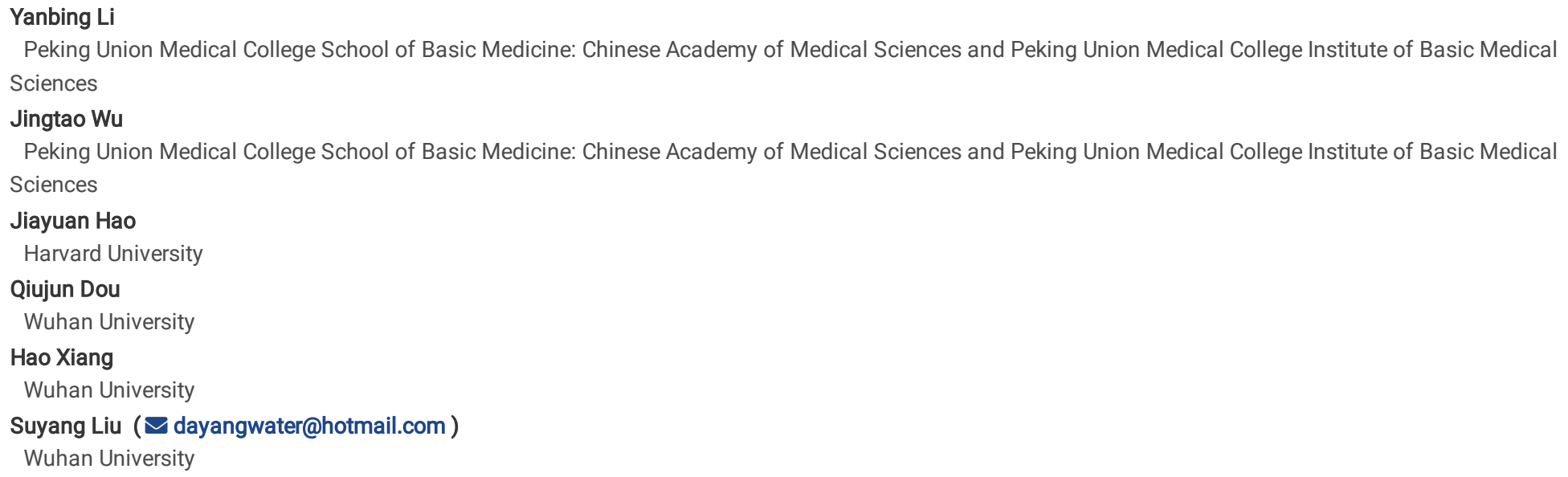

Version of Record: A version of this preprint was published at Environmental Science and Pollution Research on October 22nd, 2021. See the published version at https://doi.org/10.1007/s11356-021-16948-y. 


\section{Abstract}

Few studies have estimated the nonlinear association of ambient temperature with the risk of influenza. We therefore applied a time-series analysis to explore the short-term effect of ambient temperature on the incidence of influenza in Wuhan, China. Daily influenza cases were collected from Hubei Provincial Center for Disease Control and Prevention (Hubei CDC) from January 1st, 2014 to December 31st, 2017. The meteorological and daily pollutant data was obtained from the Hubei Meteorological Service Center and National Air Quality Monitoring Stations, respectively. We used a generalized additive model (GAM) coupled with the distributed lag nonlinear model (DLNM) to explore the exposure-lag-response relationship between the short-term risk of influenza and daily average ambient temperature. Analyses were also performed to assess the extreme cold and hot temperature effects. We observed that the ambient temperature was statistically significant, and the exposure-response curve is approximately S-shaped, with a peak observed at $23.57^{\circ} \mathrm{C}$. The single-day lag curve showed that extreme hot and cold temperatures were both significantly associated with influenza. The extreme hot temperature has an acute effect on influenza, with the most significant effect observed at lag 0-1. The extreme cold temperature has a relatively smaller effect but lasts longer, with the effect exerted continuously during a lag of 2-4 days. Our study found significant nonlinear and delayed associations between ambient temperature and the incidence of influenza. Our finding contributes to the establishment of an early warning system for airborne infectious diseases.

\section{Introduction}

Influenza virus is a single-stranded ribonucleic acid (RNA) virus with segmented negative sense which belongs to the family Orthomyxoviridae (Belser et al., 2010, Alexander, 2007, Pica et al., 2012). Influenza viruses are categorized into four types: A, B, C, and D, and the seasonal influenza epidemics are mainly caused by types A and B (Mostafa et al., 2018). As an acute respiratory infectious disease, influenza can be spread through direct contact, large droplets in short distance, and small droplets in long distance (Weber and Stilianakis, 2008, Tellier, 2009). The incubation period of influenza varies from 1 to 7 days, with an average period of two days. The main symptoms of influenza is characterized by a sudden onset of fever, cough, headache, muscle and joint pain, severe malaise (feeling unwell), sore throat, and a runny nose (WHO, 2018). The periodic emergence of new strains makes it difficult to effectively prevent and control influenza. (Kamradt-Scott, 2012, Magee et al., 2015).

Influenza has become one of the most harmful infectious diseases worldwide that cause significant morbidity and mortality (Kiruba et al., 2019). The World Health Organization (WHO) has reported that there are about 3 to 5 million cases of severe illness and 290 to 650 thousand respiratory deaths per year due to seasonal influenza (WHO, 2018). The influenza is also raging in China. It was reported that from 2010 to 2015 , the annual average number of premature respiratory deaths due to influenza in was 88,100, resulting in a huge economic burden (Li et al., 2019, Yang et al., 2015). Although the use of vaccines can adequately prevent infection, the low vaccination rate due to various reasons still makes influenza an inevitable epidemic. This, together with the effective trivalent and quadrivalent influenza vaccines not being available in many parts of the world, poses a global challenge for influenza prevention and control (Chen et al., 2020, Zhu et al., 2020).

Recent studies have suggested that meteorological factors may have an impact on influenza (Chan et al., 2009, Zhang et al., 2020, Pan et al., 2019, Pica et al., 2012). Specifically, ambient temperature is considered to be the key climate factor that affects influenza transmission (Tang et al., 2010, Yan and Wu, 2019,

Xing et al., 2017). Nevertheless, possibly due to the differences in latitudes (Chong et al., 2020) and climate regions, the relationship between temperature and influenza was not consistent. Some studies reported that a lower temperature contributed to a higher risk of influenza circulation (Liu et al., 2019 , Soebiyanto et al., 2014, Lau et al., 2019), others observed effects at higher temperatures (Zhang et al., 2020, Firestone et al., 2012, Njifon et al., 2019). In mainland China, the health effects of extreme temperature had been examined in several large cities (Ma et al., 2019, Song et al., 2018, Ma et al., 2014). Compared to the less controversial cold effect, hot effects were relatively arguable based on observations of a limited number of studies (Guo et al., 2019, Dai et al., 2018). Therefore, the potential link between temperature and influenza should be further examined.

In this study, we used the generalized additive model (GAM) to evaluate the curvilinear relationship between the incidence of influenza and ambient temperature. Co-variables include other meteorological factors and air pollutants. A distributed lag non-linear model (DLNM) was built to explore the exposurelag-response association between ambient temperature and the incidence of influenza.

\section{Materials And Methods}

\subsection{Study area}

Wuhan $\left(29^{\circ} 58^{\prime}-31^{\circ} 22^{\prime} \mathrm{N}, 113^{\circ} 41^{\prime}-115^{\circ} 05^{\prime} \mathrm{E}\right)$, the capital city of Hubei Province, China, covers an area of $8569.15 \mathrm{~km}^{2}$ and has a population of 11.4 million as of 2016 (Hao et al., 2020). Wuhan has a typical subtropical monsoon climate and a reputation of being one of the four "furnaces" in China as a result of its extreme hot temperature in summer. In the period of 2014 to 2017 , Wuhan has 21 days that mean temperature $\geq 30^{\circ} \mathrm{C}$ annually and more than 12,000 influenza cases.

\subsection{Data collection}

The meteorological data including the average daily temperature, relative humidity, wind speed, atmospheric pressure, vapor pressure, and average hourly precipitation in Wuhan city from January 1st, 2014 to December 31st, 2017 were obtained from the Hubei Meteorological Service Center. The air pollution data were collected from 10 national air quality monitoring stations in Wuhan. Daily data includes the 24-hour average concentrations of $\mathrm{SO}_{2}, \mathrm{NO}_{2}, \mathrm{PM}_{2.5}$ and $\mathrm{PM}_{10}$. The daily mean concentration of each air pollutant was averaged from concentration values collected from 10 stations at each day before including them in the analysis. 
Influenza was diagnosed and treated based on the National Health Commission of the People's Republic of China. Briefly, the influenza cases were confirmed by the clinical manifestations of influenza such as fever or headache; and a positive pathogenic test of the influenza virus. Once diagnosed, each case needs to be reported to the National Information System for Disease Control and Prevention immediately and we thus obtained the daily incidence data of influenza from this reporting system.

\subsection{Statistical analysis}

In this study, we used GAM as the first step to explore the effect of the meteorological factors and air pollutants on the incidence of influenza with the model formulated as follows:

$$
\log \left[E\left(Y_{t}\right)\right]=\beta+s(\text { Mete }) \text { or } s(\text { Pollutants })+s(\text { Time })+\text { DOW }
$$

Where, $E\left(Y_{t}\right)$ is the expected daily counts of influenza on day t; $\beta$ is the intercept; Mete are meteorological factors, including temperature, precipitation, relative humidity, precipitation, wind velocity, atmospheric pressure, and vapor pressure; Pollutants are air pollutants, including $\mathrm{SO}_{2}, \mathrm{NO}_{2}, \mathrm{PM}_{2.5}$, and $\mathrm{PM}_{10}$; Time is used to adjust long-term trend and seasonality; DOW is an indicator variable representing day of the week; $s()$ is a natural spline function representing smooth terms within GAM model formulae. The reported values of effective degree of freedom (EDF) from the GAM model demonstrate the degree of curvature of the relationship. A value of 1 for EDF is the signal as the linear shape of relationship while Value of EDF > 1 denotes more complex nonlinear relationships about influenza with Mete or Pollutants (Smiley et al., 2019). Whether the covariates have a linear relationship with influenza and whether the effect size is significant are the criteria for inclusion of these covariates in the DLNM model in the second step.

In the second step, we used DLNM to explore the exposure-lag-response relationship between the risk of influenza and daily mean ambient temperature. DLNM is a statistic model originally established by Gasparrini et al.(2010). This model is used to quantify non-linear exposure-response relationship with the delayed effect taken into consideration. The model is given below:

$$
\begin{aligned}
\log \left[E\left(Y_{t}\right)\right]=\alpha & \left.+c b(\text { Tem, } d f, \text { lag }, d f)+\sum n s\left(X_{i}, d f\right)+\text { Mete }+ \text { Pollutants }+n s \text { (Time, } d f\right) \\
& + \text { factor }(\text { DOW })
\end{aligned}
$$

Where, $E\left(Y_{t}\right)$ is the expected daily counts of influenza on day $\mathrm{t}$; $\mathrm{a}$ is the intercept; $c b(T e m, d f$, lag, $d f)$ is the cross-basis matrix of daily mean temperature and the lagged effect, which is used to explore the non-linear relationship between ambient temperature and the risk of influenza under a delayed effect scenario,

$d f$ means the degree of freedom; $\sum n s\left(X_{i}, d f\right)$ represents a natural cubic spline function for meteorological factors and air pollutants which showed a nonlinear relationship in the first step; Mete and Pollutants means meteorological factors and air pollutants that shows a linear association with the risk of influenza in the GAM, respectively; Time is used to adjust the long-term trend and DOW represents an indicator variable for day of the week.

The $c b(T e m)$ was built with $5 \mathrm{df}$ for the space of temperature and $3 \mathrm{df}$ for the log scale of lag spaces. We used the Akaike Information Criterion for quasiPoisson (Q-AIC) to determine the size of $\mathrm{df}$ in our model. All the $\mathrm{df}$ of nonlinear meteorological factors and pollutants were set to be 3 . We also conducted a sensitive analysis to alter the value of $\mathrm{df}$ from 1 to 15 for Time as an effort to find the best model fit. We ultimately determined the df of Time as 12 per year following the AIC criteria. In previous studies, the maximum lag set to the DLNM model was no more than 21 days, with the typical maximum lags as 7,14 , and 21 days (Dai et al., 2018, Lau et al., 2018, Chong et al., 2020). Considering that the incubation period of influenza is usually $0-7$ days (China, 2018), in the second sensitivity analysis, we tried to select the maximum number of lag days from a 3-21 day range, and finally determined a 7-day lag in the model according to the shape of the temperature-influenza relationship and the comprehensive result of Q-AIC. In our study, we defined the threshold temperature as the temperature when the lowest relative risk (RR) was observed. Finally, to identify the extreme weather effects, we defined the 97.5 th percentile $\left(P_{97.5}, 31.8^{\circ} \mathrm{C}\right)$ and 95 th percentile $\left(P_{95}, 30.4^{\circ} \mathrm{C}\right)$ of the average daily temperature at Wuhan as the extreme hot effect, the 2.5 th percentile $\left(P_{2.5}, 2.5^{\circ} \mathrm{C}\right)$ and the 5 th percentile $\left(\mathrm{P}_{5}, 3.1^{\circ} \mathrm{C}\right)$ were defined as the extremely cold effect.

We conducted all data analyses by R software (version3.6.1). The "mgcv" package in R was used to run GAM to explore the relationship between environmental exposures and the risk of influenza. The "dlnm" package in R was used to conduct the statistical analysis of exposure-lag-response effects.

\section{Results}

\subsection{Descriptive analysis}

Table 1 shows the summary statistics for daily cases of confirmed influenza, meteorological variables, and air pollutants. From January $1 \mathrm{st}$, 2014 to December 31 st, 2017 , a total of 12,390 confirmed cases of influenza were reported in Wuhan and the cases are increasing over time. The daily mean influenza cases were $8.49 \pm 11.75$ with the maximum number of 119 observed on December 29,2017 . During our study period, the daily average values of ambient temperature, relative humidity, wind velocity, atmospheric pressure, vapor pressure, and precipitation were $17.25^{\circ} \mathrm{C}, 78.83 \%, 1.64 \mathrm{~m} / \mathrm{s}, 1013.23 \mathrm{hPa}, 17.28$ $\mathrm{hPa}$ and $0.16 \mathrm{~mm} / \mathrm{h}$, respectively. The daily mean levels of $\mathrm{PM}_{2.5}, \mathrm{PM}_{10}, \mathrm{SO}_{2}$, and $\mathrm{NO}_{2}$ were $65.10 \mu \mathrm{g} / \mathrm{m}^{3}, 102.41 \mu \mathrm{g} / \mathrm{m}^{3}, 18.10 \mu \mathrm{g} / \mathrm{m}^{3}$, and 48.48 $\mu \mathrm{g} / \mathrm{m}^{3}$,respectively. Fig.S1 showed the seasonal fluctuations of meteorological factors, air pollutants, and cases of influenza. Influenza occurred all year round and it usually peaked in winter, sometimes in spring and summer in Wuhan. Ambient temperature, atmospheric pressure, and vapor pressure showed significant periodic patterns. 
Table 1

Description of meteorological factors, air pollutions, and influenza cases at Wuhan, China from January

\begin{tabular}{|c|c|c|c|c|c|c|}
\hline Variables & Mean \pm SD & Min & 25th & 50th & 75th & Max \\
\hline Influenza (counts/day) & $8.49 \pm 11.75$ & 0.00 & 1.00 & 8.486 & 10.00 & 119.00 \\
\hline Ambient Temperature $\left({ }^{\circ} \mathrm{C}\right)$ & $17.25 \pm 8.83$ & -4.32 & 9.57 & 18.335 & 24.79 & 33.98 \\
\hline Relative Humidity (\%) & $78.83 \pm 11.02$ & 40.67 & 71.56 & 79.33 & 87.04 & 100.00 \\
\hline Wind Velocity (m/s) & $1.64 \pm 0.89$ & 0.30 & 1.00 & 1.43 & 2.10 & 6.52 \\
\hline Atmospheric Pressure (hPa) & $1013.23 \pm 9.29$ & 994.71 & 1005.23 & 1012.90 & 1020.70 & 1041.62 \\
\hline Vapor Pressure (hPa) & $17.28 \pm 9.03$ & 2.25 & 8.66 & 16.06 & 24.89 & 37.86 \\
\hline Precipitation (mm/h) & $0.16 \pm 0.55$ & 0.00 & 0.00 & 0.16 & 0.05 & 7.88 \\
\hline $\mathrm{PM}_{2.5}\left(\mu \mathrm{g} / \mathrm{m}^{3}\right)$ & $65.10 \pm 45.73$ & 5.90 & 34.24 & 65.10 & 82.82 & 597.79 \\
\hline $\mathrm{PM}_{10}\left(\mu \mathrm{g} / \mathrm{m}^{3}\right)$ & $102.41 \pm 54.83$ & 10.88 & 63.24 & 93.90 & 131.07 & 618.30 \\
\hline $\mathrm{SO}_{2}\left(\mu \mathrm{g} / \mathrm{m}^{3}\right)$ & $18.10 \pm 13.29$ & 3.07 & 8.77 & 14.88 & 22.82 & 97.72 \\
\hline $\mathrm{NO}_{2}\left(\mu \mathrm{g} / \mathrm{m}^{3}\right)$ & $48.48 \pm 20.55$ & 11.51 & 32.86 & 44.62 & 60.54 & 162.62 \\
\hline
\end{tabular}

\subsection{Generalized additive model and correlation analysis}

The values of EDF performed by the GAM are shown in Table 2. Seven variables are statistically significant in the GAM model. Among them, four variables (relative humidity, atmospheric pressure, vapor pressure, wind velocity) have a linear relationship with influenza as the EDF value is approximately equal to 1. The EDF of $\mathrm{PM}_{10}$ and $\mathrm{PM}_{2.5}$ are 3.554, and 4.441, suggesting their nonlinear relationship with influenza. As a way of detecting the potential collinearity, Table 3 presents correlation coefficients for pairs of meteorological factors and air pollutants. The high correlation coefficients (0.843) were found between $\mathrm{PM}_{2.5}$ and $\mathrm{PM}_{10}$ and therefore we only retained $\mathrm{PM}_{2.5}$ in the model due to its greater impact on human body and that many studies had reported $\mathrm{PM} \mathrm{M}_{2.5}$ was significantly associated with influenza (Feng et al., 2016, Chen et al., 2017). Eventually, we reserved four covariates in the DLNM model: PM 2.5 as the nonlinear variable and relative humidity, wind velocity, and atmospheric pressure as the linear variables.

Table 2

Estimated degree of freedom (EDF) and P-values for the variables in the GAM model.

\begin{tabular}{|lll|}
\hline Variables & EDF & P-value \\
\hline Ambient Temperature $\left({ }^{\circ} \mathrm{C}\right)$ & 6.770 & $0.0010^{\star *}$ \\
\hline Precipitation $(\mathrm{mm} / \mathrm{h})$ & 1.003 & 0.1604 \\
\hline Relative Humidity $(\%)$ & 1.001 & $0.0100^{*}$ \\
\hline Atmospheric Pressure $(\mathrm{hPa})$ & 1.001 & $0.0001^{* *}$ \\
\hline Vapor Pressure $(\mathrm{hPa})$ & 1.000 & $0.0136^{*}$ \\
\hline Wind Velocity $(\mathrm{m} / \mathrm{s})$ & 1.001 & $0.0170^{*}$ \\
\hline $\mathrm{SO}_{2}\left(\mu \mathrm{g} / \mathrm{m}^{3}\right)$ & 3.252 & 0.2395 \\
\hline $\mathrm{NO}_{2}\left(\mu \mathrm{g} / \mathrm{m}^{3}\right)$ & 1.343 & 0.3848 \\
\hline $\mathrm{PM}_{10}\left(\mu \mathrm{g} / \mathrm{m}^{3}\right)$ & 3.554 & $0.0040^{* *}$ \\
\hline $\mathrm{PM}_{2.5}\left(\mu \mathrm{g} / \mathrm{m}^{3}\right)$ & 4.441 & $0.0209 *$ \\
\hline$* \mathrm{p}<0.05$ & & \\
\hline$* * \mathrm{p}<0.01$ & & \\
\hline
\end{tabular}

Table 3 Spearman correlation between ambient temperature, relative humidity, wind velocity, atmospheric pressure, vapor pressure, precipitation, $\mathrm{PM}_{2.5}, \mathrm{PM}_{10}$, $\mathrm{SO}_{2}$, and $\mathrm{NO}_{2}$.

${ }^{*} \mathrm{p}<0.05$

\subsection{The exposure-lag-response relationship between temperature and influenza}

Page 4/11 


\begin{tabular}{|c|c|c|c|c|c|c|c|c|c|c|}
\hline Variables & $\begin{array}{l}\text { Ambient } \\
\text { Temperature } \\
\left({ }^{\circ} \mathrm{C}\right)\end{array}$ & $\begin{array}{l}\text { Relative } \\
\text { Humidity } \\
(\%)\end{array}$ & $\begin{array}{l}\text { Wind } \\
\text { Velocity } \\
(\mathrm{m} / \mathrm{s})\end{array}$ & $\begin{array}{l}\text { Atmospheric } \\
\text { Pressure } \\
(\mathrm{hPa})\end{array}$ & $\begin{array}{l}\text { Vapor } \\
\text { Pressure } \\
\text { (hPa) }\end{array}$ & $\begin{array}{l}\text { Precipitation } \\
(\mathrm{mm} / \mathrm{h})\end{array}$ & $\mathrm{PM}_{2.5}\left(\mu \mathrm{g} / \mathrm{m}^{3}\right)$ & $\begin{array}{l}\mathrm{PM}_{10} \\
\left(\mu \mathrm{g} / \mathrm{m}^{3}\right)\end{array}$ & $\mathrm{SO}_{2}\left(\mu \mathrm{g} / \mathrm{m}^{3}\right)$ & $\mathrm{NO}_{2}(\mu \mathrm{g} /$ \\
\hline
\end{tabular}

Ambient
Temperature
$\left({ }^{\circ} \mathrm{C}\right)$

\begin{tabular}{|c|c|c|c|c|c|c|c|c|c|c|}
\hline $\begin{array}{l}\text { Relative } \\
\text { Humidity (\%) }\end{array}$ & -0.0233 & 1 & & & & & & & & \\
\hline $\begin{array}{l}\text { Wind Velocity } \\
(\mathrm{m} / \mathrm{s})\end{array}$ & 0.0094 & $-0.1046^{\star}$ & 1 & & & & & & & \\
\hline $\begin{array}{l}\text { Atmospheric } \\
\text { Pressure (hPa) }\end{array}$ & $-0.8836^{\star}$ & $-0.1474^{\star}$ & -0.0135 & 1 & & & & & & \\
\hline $\begin{array}{l}\text { Vapor } \\
\text { Pressure (hPa) }\end{array}$ & $0.9493^{\star}$ & $0.2009 *$ & -0.0094 & $-0.8795^{\star}$ & 1 & & & & & \\
\hline $\begin{array}{l}\text { Precipitation } \\
(\mathrm{mm} / \mathrm{h})\end{array}$ & $0.0733^{*}$ & $0.3235^{\star}$ & $0.1495^{\star}$ & $-0.1691 *$ & $0.1575^{\star}$ & 1 & & & & \\
\hline $\mathrm{PM}_{2.5}\left(\mu \mathrm{g} / \mathrm{m}^{3}\right)$ & $-0.4795^{\star}$ & -0.0579 & -0.0150 & $0.4432^{\star}$ & $-0.4905^{\star}$ & $-0.1027 *$ & 1 & & & \\
\hline $\mathrm{PM}_{10}\left(\mu \mathrm{g} / \mathrm{m}^{3}\right)$ & $-0.2585^{\star}$ & $-0.2228^{*}$ & -0.0398 & 0.2720 * & $-0.3356^{*}$ & -0.1110 * & $0.8434^{*}$ & 1 & & \\
\hline $\mathrm{SO}_{2}\left(\mu \mathrm{g} / \mathrm{m}^{3}\right)$ & $-0.3710 *$ & $-0.2386^{\star}$ & $-0.0796^{*}$ & $0.3366^{*}$ & $-0.4392^{\star}$ & -0.0950 * & $0.6256^{\star}$ & $0.6349 *$ & 1 & \\
\hline $\mathrm{NO}_{2}\left(\mu \mathrm{g} / \mathrm{m}^{3}\right)$ & $-0.2284^{*}$ & $-0.1431^{\star}$ & $-0.2101 *$ & $0.2489 *$ & $-0.3053^{\star}$ & $-0.0997 *$ & $0.6294^{*}$ & $0.7062^{\star}$ & $0.6443^{*}$ & 1 \\
\hline
\end{tabular}

We found a nonlinear relationship between the daily average temperature and the risk of influenza, which was S-shaped in the overall cumulative effect analyses (Fig. 1). The risk of influenza gradually decreased until it reached the threshold temperature $\left(3.90^{\circ} \mathrm{C}\right)$. When the mean temperature was higher than $3.90^{\circ} \mathrm{C}$, there was a significant positive association between the temperature and the risk of influenza with a peak appeared at $23.57^{\circ} \mathrm{C}(\mathrm{RR}=2.604,95 \% \mathrm{Cl}$ : 1.462-4.639). The three-dimension (3D) plot illustrates a visualized exposure-lag-response relationship between average mean temperature and the risk of influenza (Fig. 2).

\subsection{The extreme hot and cold effects}

Figure 3 shows the effect of ambient temperature on influenza by lag and the lagged risk of influenza at selected extreme hot and cold temperatures. The left column shows the associations between temperature and influenza at selected lags. At lag 0 , as the temperature rises, the RR of influenza continues to increase, reaching a peak of $25.51^{\circ} \mathrm{C}$. $(\mathrm{RR}=1.809,95 \% \mathrm{Cl}: 1.289-2.541)$. At lag1, the temperature and the risk of influenza shows a non-linear S-shaped pattern, with a peak observed at $25.22^{\circ} \mathrm{C}(\mathrm{RR}=1.291,95 \% \mathrm{Cl}: 1.119-1.490)$. The pattern seemed to be consistent at lag $2-4$ and the risk of influenza incidence decreases as the temperature rises with the maximum RR appeared at $-4.32^{\circ} \mathrm{C}$. At lag $5-7$, the relationship between temperature and the risk of influenza was not significant.

From the right column of Fig. 3, we observed that the effects of extreme cold temperature presented an inverted ' $V$ ' shape that initially exhibited a protective effect started at lag 0 and then peaked at lag 3. Influenza is very sensitive to extremely hot temperature and the peaks occurred immediately at lag 0 . The RR values were 1.726 (95\% Cl: 1.152-2.587) and 1.754 (95\% Cl: 1.194-2.578) for $\mathrm{P}_{97.5}$ and $\mathrm{P}_{95}$ temperatures, respectively. Compared with the extremely hot effect, the extremely cold effect is more mild but lasting longer. For low temperatures, the effect estimates at the $P_{2.5}$ was greater than estimates at the $P_{5}$, while for high temperatures, the risk of Influenza at the $\mathrm{P}_{95}$ was higher than at the $\mathrm{P}_{97.5}$. The detailed information was shown in Table $\mathrm{S} 1$.

We also explored the cumulative effects of extremely hot and cold temperatures on influenza from lag0-1 to lag0-7. We found the extremely low temperature only presented a significant protective effect at lag $0-1$, and the effect of $P_{2.5}$ was stronger than $P_{5}\left(\right.$ Table S2). The cumulative hot effects of $P_{95}$ and $P_{97.5}$ both showed significant negative effects from 0-1 days to 0-7 lags. In terms of cumulative effects, extremely hot temperature had more significant effect on the risk of influenza than extremely cold temperature.

\section{Discussion}

In this study, we found the ambient temperature was significantly associated with the incidence of influenza in Wuhan, China. Our study indicated that there were significant nonlinear and delayed effects of cold and hot temperatures on influenza. Hot temperatures showed a considerably higher risk for influenza than cold temperatures. We found an acute and strong association between high temperature and influenza, while low temperature was observed to have a mild but lasting effect on influenza. Our findings provide further epidemiological evidence to explore the unclear mechanism of how ambient temperature affects influenza outbreaks.

This study found that the association between temperature and the incidence of influenza presented an approximate ' $S$ ' shape from January 1 st, 2014 to December $31 \mathrm{st}, 2017$, with the highest cumulative RR observed at $23.57^{\circ} \mathrm{C}(\mathrm{RR}=2.604,95 \% \mathrm{Cl}: 1.462-62639)$. A study conducted in another subtropical region-Shanghai also used DLNM to explore the relationship between climate change and influenza from 2012 to 2018 (Zhang et al., 2020 ). Consistent with our findings, this study showed the similar shape between temperature and influenza A, with two peaks at $1.4^{\circ} \mathrm{C}$ and $25.8^{\circ} \mathrm{C}$. However, various previous studies 
observed both linear and non-linear exposure-response relationships between temperature and influenza. Some spotted linear patterns of temperature on influenza (Liu et al., 2019, Soebiyanto et al., 2014) while most others noticed the non-linear relationships between temperature and influenza (Guo et al., 2019, Zhang et al., 2015, Peci et al., 2019, Liu et al., 2018, Lytras et al., 2019). For example, a study in Jiangsu Province, China observed an M-shaped relationship for influenza-like illness and influenza A virus, and an inverted U-shaped pattern for influenza B virus (Dai et al., 2018). A Chinese multi-city study including six cities reported that different cities had different exposure-response shapes, although only one city found a statistically significant relationship (Lau et al., 2018). In addition to the different model settings, the heterogeneity in the shape of non-linear relationships might result from differences in various geographic and climatic characteristics including latitudes, atmospheric dispersal, sunspots, sunlight, and vitamin D levels (Tang et al., 2010, Tamerius et al., 2013).

We found the cold effect became predominant at lag 2 and lasted for 3 days, while the hot effect was strong immediate after exposure from lag 0 to lag 1. Similar to our findings, others also reported the acute and shorter-term effect of high temperature on influenza (Ma et al., 2019, Islam et al., 2017). We might be able to attribute it to that some people preferred to seek medical attention soon after infection while others would not do it unless severe symptoms appeared (Apostolidis et al., 2009). Thus, the hot temperature may prompt patients to seek medical treatment faster (Dai et al., 2018). Moreover, a previous study found the positive association between temperature and host activity (Belanger et al., 2009). Therefore, high temperature may increase the chance of contact with the contaminated objects and make it easier for contact transmission spread immediately (Dai et al., 2018).

We observed different patterns of the lagged effects for extremely low temperatures. The extremely cold temperature exhibited a protective effect at lag 0 and then started to show a negative effect at lag 1. The protective effect may be explained by the awareness of seeking medical assistance. On cold days, people tend to avoid medical attention immediately after infection and this led to the underestimate of reported cases. Consistent with previous studies, we have also observed persistent cold effects (Peci et al., 2019, Guo et al., 2019). Various hypotheses were proposed to explain the phenomenon that low temperatures favored increased influenza cases. Low temperature may prolong the survival of viral particles, and make more people crowded indoors to increase exposure (Zhang et al., 2020, Chong et al., 2015). Eccles et al. reported that inhalation of cold air was associated with a reduction in the nasal epithelium temperature which was sufficient to inhibit immune defenses against infection (Eccles, 2002). Besides, a laboratory study using guinea pig models has indicated that the cold temperature enhances the spread of influenza viruses in the air by increasing and prolonging the virus emissions of the vaccinated animals (Pica et al., 2012).

We also observed an increased risk of influenza on hot days which was consistent with many previous studies as well (Firestone et al., 2012, Lytras et al., 2019). For instance, the study conducted in Australia observed a higher risk of infection at a variety of high temperatures $\left(>28^{\circ} \mathrm{C}\right)$. However, a study in Guilin, China showed no significant association between the hot effect and influenza (Guo et al., 2019). Some studies indicated that high temperature was negatively associated with the influenza risk in different countries (Peci et al., 2019, Lau et al., 2019, Liu et al., 2019). the underlying reason for the association remains unclear, but the findings of previous studies may help to make possible explanations. Paul K.S. Chan claimed that the peak of influenza epidemic in summer

is the direct or indirect result of the increase in the use of indoor air-conditioning (Chan et al., 2009). People like spending more time indoors in a more crowded and air-conditioned environment where the conditions are cooler and dryer, contributing to influenza epidemic (Tang et al., 2010). In addition, an animal study found that higher temperatures $\left(20-30^{\circ} \mathrm{C}\right)$ blocked aerosol transmission of influenza and the contact or short-range spread became the major transmission route under hot conditions (Lowen et al., 2008).

Unlike previous studies (Lytras et al., 2019, Guo et al., 2019, Zhang et al., 2020), we found the hot effect was generally stronger than cold effect. This result remained robust after we adjusted the lag period from lag0-1 to lag0-6. It may be a result of the existing potential confounding factors such as relative humidity. Guinea pig models have shown that transmission of human influenza viruses was most efficient under cold temperature and low relative humidity conditions (Lowen and Steel, 2014, Lowen et al., 2007, Chan et al., 2009). Wuhan often experiences humid weather regardless of cold winter and hot summer with the mean $\mathrm{RH}$ equals to $78.83 \%$. Animal models have shown that transmission frequency at high temperature $\left(20\right.$ or $\left.23^{\circ} \mathrm{C}\right)$ was higher than at low temperature $\left(5^{\circ} \mathrm{C}\right)$ among guinea pigs and ferrets at the constant high RH (> 70\%) (Lowen and Steel, 2014, Gustin et al., 2015). As the relative humidity in Wuhan was high all year around, the observed stronger hot effects than cold effects is reasonable.

This study has some limitations that should be acknowledged. Firstly, this is a single-city study. So, without parallel studies conducted in other cities we cannot ascertain the generalizability of the results. Secondly, due to the limited data, we cannot estimate the risk of the specific influenza subtype. Third, the meteorological and air pollutant data were collected from outdoor stations and they may not fully represent the accurate indoor climate and individual conditions. Finally, due to no data available our analysis does not include other important risk factors that may affect influenza outbreaks, for example, demographic characteristics and contact patterns (Schmidt-Ott et al., 2016).

\section{Conclusions}

Our study found significant nonlinear and delayed associations between ambient temperature and influenza. Hot temperatures exhibited more acute impact and much higher risk for the incidence of influenza than cold temperatures. Our findings on the effects at different lag days may help policy makers develop appropriate early warning systems to prevent future outbreaks.

\section{Declarations}

\section{Ethics approval and consent to participate}

Not applicable.

\section{Consent for publication}


All authors consent when it is published.

\section{Availability of data and materials}

The datasets generated and/or analysed during the current study are not publicly available due [The case data was obtained from Hubei Provincial Center for Disease Control and Prevention (Hubei $\mathrm{CDC}$ ) and we were not authorized to share original data publicly] but are available from the corresponding author on reasonable request.

\section{Competing interests}

The authors declare that they have no competing interests

\section{Funding}

Not applicable.

\section{Authors' contributions}

All authors contributed to the study conception and design. Material preparation, data collection and analysis were performed by [Suyang Liu], [Hao Xiang], [Jiayuan Hao], and [Qiujun Dou]. The first draft of the manuscript was written by [Yanbing Li] and [Jingtao Wu]. All authors commented on previous versions of the manuscript. All authors read and approved the final manuscript.

\section{Acknowledgements}

The author is grateful to the editor and the anonymous reviewers for their valuable comments that substantially improved this manuscript.

\section{References}

1. Alexander, D. J. (2007). An overview of the epidemiology of avian influenza. Vaccine, 25(30), 5637-5644.

2. Apostolidis, A., Kirana, P. S., Chiu, G., Link, C., Tsiouprou, M., \& Hatzichristou, D. (2009). Gender and age differences in the perception of bother and health care seeking for lower urinary tract symptoms: results from the hospitalised and outpatients' profile and expectations study. European urology, 56(6), 937947.

3. Bélanger, M., Gray-Donald, K., O'loughlin, J., Paradis, G., \& Hanley, J. (2009). Influence of weather conditions and season on physical activity in adolescents. Annals of epidemiology, 19(3), 180-186.

4. Belser, J. A., Maines, T. R., Tumpey, T. M., \& Katz, J. M. (2010). Influenza A virus transmission: contributing factors and clinical implications. Expert reviews in molecular medicine, 12 .

5. Chan, P. K., Mok, H. Y., Lee, T. C., Chu, I. M., Lam, W. Y., \& Sung, J. J. (2009). Seasonal influenza activity in Hong Kong and its association with meteorological variations. Journal of medical virology, 81(10), 1797-1806.

6. Chen, G., Zhang, W., Li, S., Zhang, Y., Williams, G., Huxley, R., ... \& Guo, Y. (2017). The impact of ambient fine particles on influenza transmission and the modification effects of temperature in China: A multi-city study. Environment international, 98, 82-88.

7. Chen, Q., Wang, L., Xie, M., Li, X., \& Recommendations for Influenza, Streptococcus pneumoniae Vaccination in Elderly People in China Writing Group, Geriatric Respiratory Group and Chinese Society of Geriatrics. (2020). Recommendations for influenza and Streptococcus pneumoniae vaccination in elderly people in China. Aging Medicine, 3(1), 4-14.

8. CHINA, N. H. C. O. T. P. S. R. O. 2018. Guideline for Diagnosis and Treatment of Infuenza (Revision 2018). Infectious Disease Information, $31,500-504$.

9. Chong, K. C., Goggins, W., Zee, B. C. Y., \& Wang, M. H. (2015). Identifying meteorological drivers for the seasonal variations of influenza infections in a subtropical city-Hong Kong. International journal of environmental research and public health, 12(2), 1560-1576.

10. Chong, K. C., Liang, J., Jia, K. M., Kobayashi, N., Wang, M. H., Wei, L., ... \& Sumi, A. (2020). Latitudes mediate the association between influenza activity and meteorological factors: A nationwide modelling analysis in 45 Japanese prefectures from 2000 to 2018. Science of The Total Environment, 703, 134727.

11. Dai, Q., Ma, W., Huang, H., Xu, K., Qi, X., Yu, H., .. \& Huo, X. (2018). The effect of ambient temperature on the activity of influenza and influenza like illness in Jiangsu Province, China. Science of The Total Environment, 645, 684-691.

12. Eccles, R. (2002). An explanation for the seasonality of acute upper respiratory tract viral infections. Acta oto-laryngologica, 122(2), 183-191.

13. Feng, C., Li, J., Sun, W., Zhang, Y., \& Wang, Q. (2016). Impact of ambient fine particulate matter (PM 2.5) exposure on the risk of influenza-like-illness: a time-series analysis in Beijing, China. Environmental Health, 15(1), 17.

14. Firestone, S. M., Cogger, N., Ward, M. P., Toribio, J. A. L., Moloney, B. J., \& Dhand, N. K. (2012). The influence of meteorology on the spread of influenza: survival analysis of an equine influenza (A/H3N8) outbreak. PLoS One, 7(4), e35284.

15. Gasparrini, A., Armstrong, B., \& Kenward, M. G. (2010). Distributed lag non-linear models. Statistics in medicine, 29(21), 2224-2234.

16. Guo, Q., Dong, Z., Zeng, W., Ma, W., Zhao, D., Sun, X., ... \& Hu, W. (2019). The effects of meteorological factors on influenza among children in Guangzhou, China. Influenza and other respiratory viruses, 13(2), 166-175.

17. Gustin, K. M., Belser, J. A., Veguilla, V., Zeng, H., Katz, J. M., Tumpey, T. M., \& Maines, T. R. (2015). Environmental conditions affect exhalation of H3N2 seasonal and variant influenza viruses and respiratory droplet transmission in ferrets. PloS one, 10(5), e0125874.

Page $7 / 11$ 
18. Hao, J., Yang, Z., Yang, W., Huang, S., Tian, L., Zhu, Z., ... \& Liu, S. (2020). Impact of Ambient Temperature and Relative Humidity on the Incidence of HandFoot-Mouth Disease in Wuhan, China. International journal of environmental research and public health, 17(2), 428.

19. Islam, M. S., Chaussalet, T. J., \& Koizumi, N. (2017). Towards a threshold climate for emergency lower respiratory hospital admissions. Environmental research, 153, 41-47.

20. Kamradt-Scott, A. (2012). Changing perceptions: Of pandemic influenza and public health responses. American journal of public health, $102(1), 90-98$.

21. Kiruba, R., Babu, B. S., Sheriff, A. K., Gunasekaran, P., Anupama, C. P., Saran, N., ... \& Kaveri, K. (2019). Dynamics of the occurrence of influenza in relation to seasonal variation in Chennai, Tamil Nadu: A 7-year cumulative study. Indian Journal of Medical Microbiology, $37(3), 401$.

22. Lao, J. H., Liu, Z. D., Liu, Y. Y., Zhang, J., \& Jiang, B. F. (2018). Influence of diurnal temperature range on influenza incidence in the elderly. Zhonghua liu xing bing xue za zhi= Zhonghua liuxingbingxue Zazhi, 39(11), 1454-1458.

23. Lau, S. Y. F., Chen, E., Wang, M., Cheng, W., Zee, B. C. Y., Han, X., ... \& Wang, X. (2019). Association between meteorological factors, spatiotemporal effects, and prevalence of influenza A subtype $\mathrm{H7}$ in environmental samples in Zhejiang province, China. Science of The Total Environment, 663, 793-803.

24. Lau, S. Y. F., Wang, X., Wang, M., Liu, S., Zee, B. C. Y., Han, X., ... \& Chen, E. (2018). Identification of meteorological factors associated with human infection with avian influenza A H7N9 virus in Zhejiang Province, China. Science of the total environment, 644, 696-709.

25. Li, L., Liu, Y., Wu, P., Peng, Z., Wang, X., Chen, T., ... \& Lau, Y. C. (2019). Influenza-associated excess respiratory mortality in China, 2010-15: a populationbased study. The Lancet Public health, 4(9), e473-e481.

26. Liu, T., Kang, M., Zhang, B., Xiao, J., Lin, H., Zhao, Y., ... \& Ma, W. (2018). Independent and interactive effects of ambient temperature and absolute humidity on the risks of avian influenza A (H7N9) infection in China. Science of The Total Environment, 619, 1358-1365.

27. Liu, Z., Zhang, J., Zhang, Y., Lao, J., Liu, Y., Wang, H., \& Jiang, B. (2019). Effects and interaction of meteorological factors on influenza: Based on the surveillance data in Shaoyang, China. Environmental research, 172, 326-332.

28. Lowen, A. C., \& Steel, J. (2014). Roles of humidity and temperature in shaping influenza seasonality. Journal of virology, 88(14), 7692-7695.

29. Lowen, A. C., Mubareka, S., Steel, J., \& Palese, P. (2007). Influenza virus transmission is dependent on relative humidity and temperature. PLoS Pathog, 3(10), e151.

30. Lowen, A. C., Steel, J., Mubareka, S., \& Palese, P. (2008). High temperature (30 C) blocks aerosol but not contact transmission of influenza virus. Journal of virology, 82(11), 5650-5652.

31. Lytras, T., Pantavou, K., Mouratidou, E., \& Tsiodras, S. (2019). Mortality attributable to seasonal influenza in Greece, 2013 to 2017 : variation by type/subtype and age, and a possible harvesting effect. Eurosurveillance, 24(14), 1800118.

32. Ma, W., Chen, R., \& Kan, H. (2014). Temperature-related mortality in 17 large Chinese cities: how heat and cold affect mortality in China. Environmental research, 134, 127-133.

33. Ma, Y., Zhou, J., Yang, S., Yu, Z., Wang, F., \& Zhou, J. (2019). Effects of extreme temperatures on hospital emergency room visits for respiratory diseases in Beijing, China. Environmental Science and Pollution Research, 26(3), 3055-3064.

34. Magee, D., Beard, R., Suchard, M. A., Lemey, P., \& Scotch, M. (2015). Combining phylogeography and spatial epidemiology to uncover predictors of H5N1 influenza A virus diffusion. Archives of virology, 160(1), 215-224.

35. Mostafa, A., Abdelwhab, E. M., Mettenleiter, T. C., \& Pleschka, S. (2018). Zoonotic potential of influenza A viruses: a comprehensive overview. Viruses, 10(9), 497.

36. Munshili Njifon, H. L., Monamele, C. G., Kengne Nde, C., Vernet, M. A., Bouba, G., Tchatchouang, S., ... \& Njouom, R. (2019). Influence of meteorological parameters in the seasonality of influenza viruses circulating in Northern Cameroon. Influenza and Other Respiratory Viruses, 13(2), 158-165.

37. Pan, M., Yang, H. P., Jian, J., Kuang, Y., Xu, J. N., Li, T. S., ... \& Li, W. Y. (2019). Association of meteorological factors with seasonal activity of influenza A subtypes and $B$ lineages in subtropical western China. Epidemiology \& Infection, 147.

38. Peci, A., Winter, A. L., Li, Y., Gnaneshan, S., Liu, J., Mubareka, S., \& Gubbay, J. B. (2019). Effects of absolute humidity, relative humidity, temperature, and wind speed on influenza activity in Toronto, Ontario, Canada. Applied and environmental microbiology, 85(6).

39. Pica, N., Chou, Y. Y., Bouvier, N. M., \& Palese, P. (2012). Transmission of influenza B viruses in the guinea pig. Journal of virology, 86(8), $4279-4287$.

40. Schmidt-Ott, R., Schwehm, M., \& Eichner, M. (2016). Influence of social contact patterns and demographic factors on influenza simulation results. BMC infectious diseases, 16(1), 646.

41. Smiley, A., King, D., \& Bidulescu, A. (2019). The association between sleep duration and metabolic syndrome: the NHANES 2013/2014. Nutrients, 11(11), 2582.

42. Soebiyanto, R. P., Clara, W., Jara, J., Castillo, L., Sorto, O. R., Marinero, S., ... \& Kiang, R. K. (2014). The role of temperature and humidity on seasonal influenza in tropical areas: Guatemala, El Salvador and Panama, 2008-2013. PLoS One, 9(6), e100659.

43. Song, X., Wang, S., Li, T., Tian, J., Ding, G., Wang, J., ... \& Shang, K. (2018). The impact of heat waves and cold spells on respiratory emergency department visits in Beijing, China. Science of the Total Environment, 615, 1499-1505.

44. Su, W., Liu, T., Geng, X., \& Yang, G. (2020). Seasonal pattern of influenza and the association with meteorological factors based on wavelet analysis in Jinan City, Eastern China, 2013-2016. PeerJ, 8, e8626.

45. Tamerius, J. D., Shaman, J., Alonso, W. J., Bloom-Feshbach, K., Uejio, C. K., Comrie, A., \& Viboud, C. (2013). Environmental predictors of seasonal influenza epidemics across temperate and tropical climates. PLoS Pathog, 9(3), e1003194.

46. Tang, J. W., Lai, F. Y., Nymadawa, P., Deng, Y. M., Ratnamohan, M., Petric, M., ... \& Wong, F. Y. (2010). Comparison of the incidence of influenza in relation to climate factors during 2000-2007 in five countries. Journal of medical virology, 82(11), 1958-1965. 
47. Tellier, R. (2009). Aerosol transmission of influenza A virus: a review of new studies. Journal of the Royal Society Interface, 6(suppl_6), S783-S790.

48. Wang, X. L., Yang, L., He, D. H., Chiu, A. P., Chan, K. H., Chan, K. P., ... \& Hu, W. (2017). Different responses of influenza epidemic to weather factors among Shanghai, Hong Kong, and British Columbia. International journal of biometeorology, 61(6), 1043-1053.

49. Weber, T. P., \& Stilianakis, N. I. (2008). Inactivation of influenza A viruses in the environment and modes of transmission: a critical review. Journal of infection, 57(5), 361-373.

50. WHO 2018. Fact sheet on Influenza (Seasonal): Epidemiology, updated November 2018. Available at: https://www.who.int/news-room/factsheets/detail/influenza-(seasonal)/ (accessed 8 May 2021)

51. Xing, Y., Song, L., Sun, G. Q., Jin, Z., \& Zhang, J. (2017). Assessing reappearance factors of H7N9 avian influenza in China. Applied Mathematics and Computation, 309, 192-204.

52. Min, Y. S., \& Guang, W. U. (2019). Impact of Temperature on Influenza A Status during Global Warming Hiatus. Biomedical and Environmental Sciences, 32(7), 554-557.

53. Yang, J., Jit, M., Leung, K. S., Zheng, Y. M., Feng, L. Z., Wang, L. P., ... \& Yu, H. J. (2015). The economic burden of influenza-associated outpatient visits and hospitalizations in China: a retrospective survey. Infectious diseases of poverty, 4(1), 44.

54. Yang, W., Cummings, M. J., Bakamutumaho, B., Kayiwa, J., Owor, N., Namagambo, B., ... \& Shaman, J. (2018). Dynamics of influenza in tropical Africa: Temperature, humidity, and co-circulating (sub) types. Influenza and other respiratory viruses, 12(4), 446-456.

55. Zhang, Y., Feng, C., Ma, C., Yang, P., Tang, S., Lau, A., ... \& Wang, Q. (2015). The impact of temperature and humidity measures on influenza A (H7N9) outbreaks-evidence from China. International Journal of Infectious Diseases, 30, 122-124.

56. Zhang, Y., Li, C., Feng, R., Zhu, Y., Wu, K., Tan, X., \& Ma, L. (2016). The short-term effect of ambient temperature on mortality in Wuhan, China: a time-series study using a distributed lag non-linear model. International journal of environmental research and public health, $13(7), 722$.

57. Zhang, Y., Ye, C., Yu, J., Zhu, W., Wang, Y., Li, Z., ... \& Hu, W. (2020). The complex associations of climate variability with seasonal influenza A and B virus transmission in subtropical Shanghai, China. Science of The Total Environment, 701, 134607.

58. Zhu, A., Liu, J., Ye, C., Yu, J., Peng, Z., Feng, L., ... \& Li, Z. (2020). Characteristics of Seasonal Influenza Virus Activity in a Subtropical City in China, 20132019. Vaccines, 8(1), 108.

\section{Figures}

\section{Ambient Temperature}

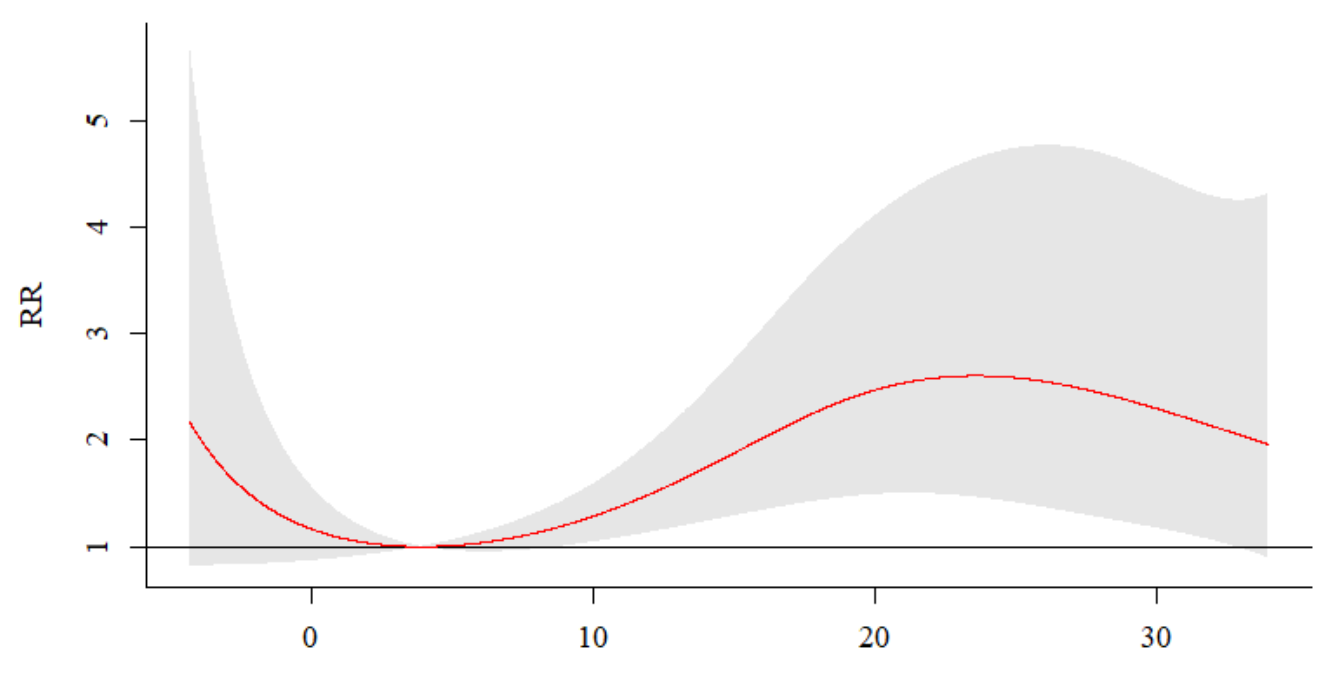

$\left({ }^{\circ} \mathrm{C}\right)$

Figure 1

The cumulative association between ambient temperature and the risk of influenza over a lagged period of 0-7days. 
Ambient Temperature

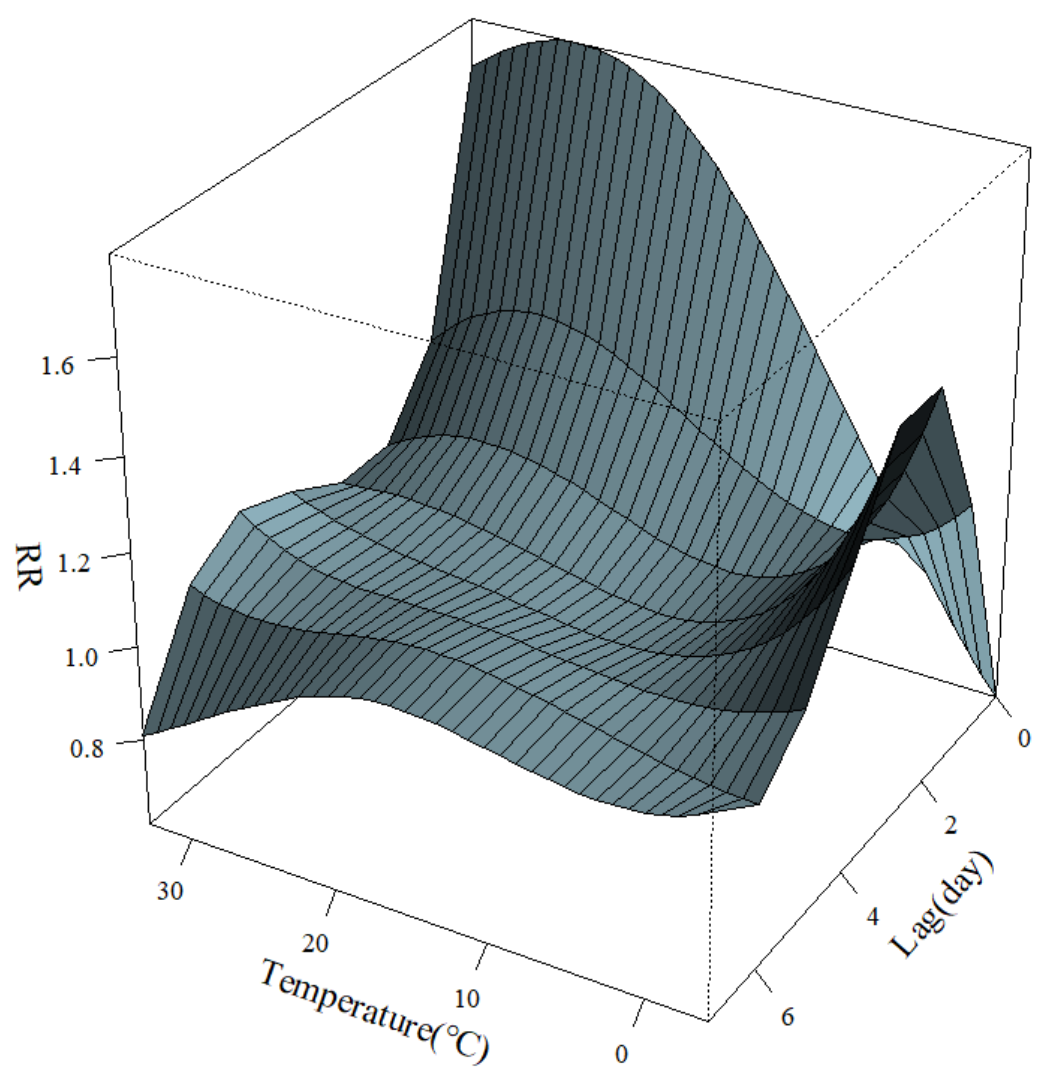

Figure 2

Three-dimensional (3D) exposure-lag-response plot for temperature and the risk influenza. 
Lagged day $=0$

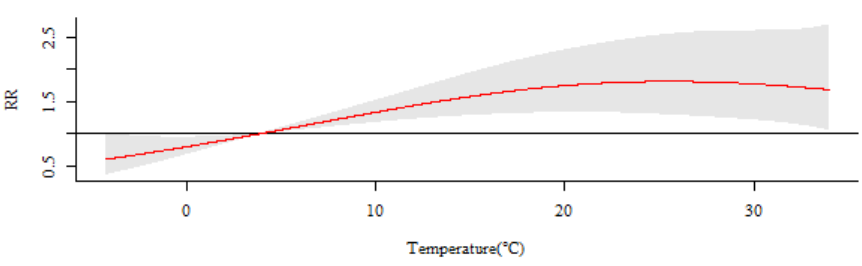

Lagged day $=1$

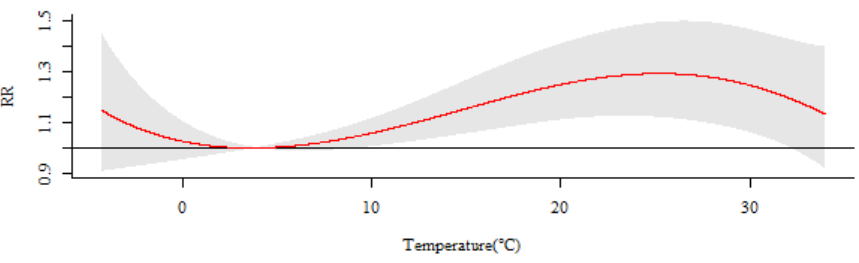

Lagged day $=4$

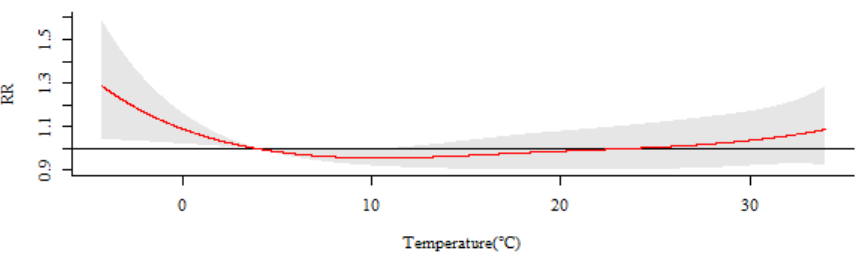

Lagged day $=7$

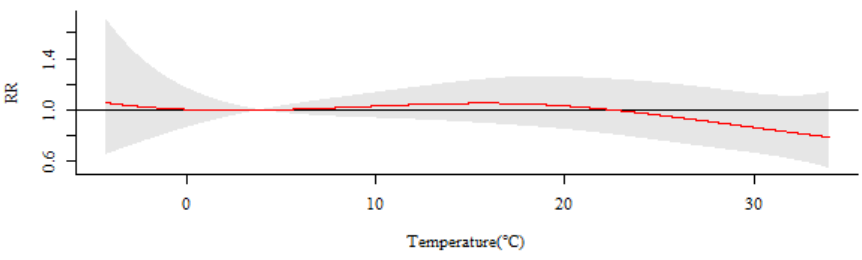

Ambient temperature $=2.5$

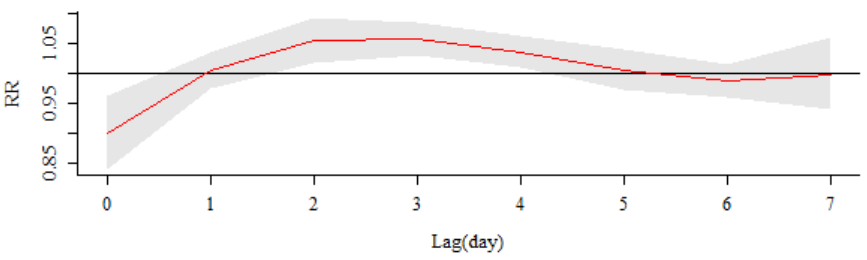

Ambient temperature $=3.1$

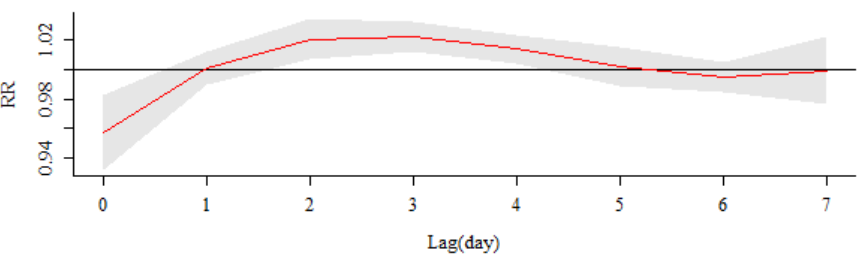

Ambient temperature $=\mathbf{3 0 . 4}$

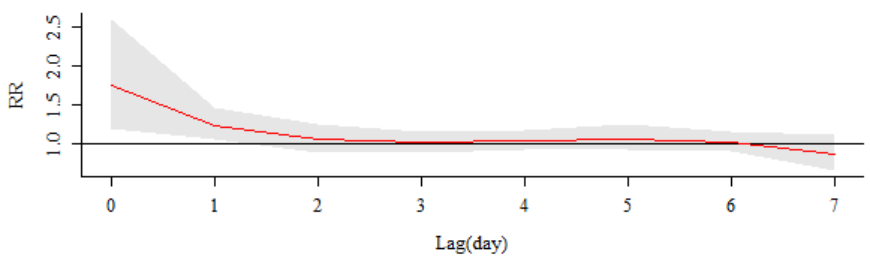

Ambient temperature $=31.8$

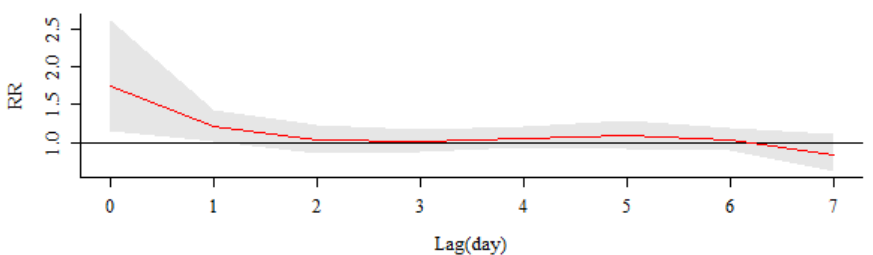

\section{Figure 3}

Relative risk of influenza associated with ambient temperature at selected lags (left), and relative risk of influenza of the lag period at selected extremely hot and cold effects (right).

\section{Supplementary Files}

This is a list of supplementary files associated with this preprint. Click to download.

- Supplementary.docx 